\title{
1 Quantitative evaluation of multi-wall carbon nanotube uptake by terrestrial plants
}

2 Qing Zhao ${ }^{\mathrm{a}, \mathrm{b}, \mathrm{d}, \dagger,{ }^{*}}$, Chuanxin Ma ${ }^{\mathrm{b}, \mathrm{c}, \dagger}, \mathrm{Jason}^{\mathrm{C}}$. White ${ }^{\mathrm{c}}$, Om Parkash Dhankher $^{\mathrm{b}}$, Xuejiao

3 Zhang ${ }^{\text {a, }}$, Siyu Zhang ${ }^{\text {a,d }}$ and Baoshan Xing ${ }^{\text {b, * }}$

$4 \quad{ }^{\mathrm{a}}$ Institute of Applied Ecology, Chinese Academy of Sciences, Shenyang 110016, China

$5 \quad{ }^{\mathrm{b}}$ Stockbridge School of Agriculture, University of Massachusetts, Amherst, MA 01003, USA

$6{ }^{\mathrm{c}}$ Department of Analytical Chemistry, The Connecticut Agricultural Experiment Station, New

7 Haven, CT 06504, United States

$8 \quad{ }^{\mathrm{d}}$ Key Laboratory of Pollution Ecology and Environmental Engineering, Institute of Applied

9 Ecology, Chinese Academy of Sciences, Shenyang 110016, China

10

11

12

13

14

15

16

17

18

19

20

$21{ }^{\dagger}$ These authors contributed equally to the paper.

* Corresponding author. Tel: +1 413 545-5212. E-mail: bx@umass.edu (Baoshan Xing); 
24 ABSTRACT: The extent and mechanisms by which multi-wall carbon nanotubes (MWCNTs) are accumulated by terrestrial plant species is currently unknown. In this study, we successfully measured the MWCNTs content in different plant (Arabidopsis thaliana, rice, maize and soybean) using ${ }^{14} \mathrm{C}$ labeled MWCNTs. Quantitative relationships among the uptake amount of MWCNTs in different Arabidopsis tissues, the physiological (water loss, pigment content, and total protein content) and biochemical parameters (antioxidant enzyme activities) were further evaluated. Our results indicated that changes in biochemical parameters were much more sensitive than physiological parameters. The lowest CAT activities in the treatment with (1,3dinitrobenzene + MWCNTs) were only 0.13-fold of that in the 1,3-dinitrobenzene alone treatment, suggesting MWCNTs could alleviate the toxicity to Arabidopsis. Due to the toxicity caused by small polar aromatic organic molecules (SPAOMs), the MWCNTs uptake in leaf in the treatment with (2,4-dichlorophenol + MWCNTs) was only 0.07-fold relative to the MWCNTs alone treatment. Hydrodynamic diameter of MWCNTs in solution did not significantly affect MWCNTs uptake. Uptake models for MWCNTs into root and leaf tissue were constructed via stepwise multiple linear regression analysis. This study will provide important information for the accurate determination of risk associated with MWCNT exposure.

0

\section{Introduction}


Carbon nanotubes (CNTs) are allotropes of carbon with a cylindrical nanostructure [1] that can form both naturally [2-4] and artificially. Due to their unique electronic, optical, thermal, and photoactive properties, carbon nanotubes (CNTs) have been applied widely [5]. Current global multi-wall CNTs (MWCNTs) production capacity is estimated to be 13,996 tons [1]. With a sharply increasing demand and use for CNTs [1], these materials will inevitably be released into the environment during production, transport, handling, use and disposal, with soil being a primary source and sink. Gottschalk et al. forecasted that the annual input of CNTs into agricultural soils treated with sewage sludge could be increased by $74 \mathrm{ng} / \mathrm{kg}$ based on CNTs input data from 2008 [6]. Owing to their inherent hydrophobicity, the concentration of CNTs in soil could be approximately 20-fold higher than in water [7]. As such, CNT exposure to terrestrial plants is likely. CNTs accumulated by crops could bioaccumulated and biomagnify along the food chain, eventually leading to human exposure [8-15]. Since CNTs may pose a significant risk to ecological and human health, it is essential to understand their toxicity, uptake, and translocation of CNTs in plant [8, 16-19].

CNT accumulation has been reported to vary considerably among different plant species [8, 12, 20-24]. No accumulation was reported in the roots of cabbage [20], carrot [20], cucumber [20], lettuce [20], onion [20], tomato [20], Alfalfa [21] and wheat [21]. However, CNTs uptake by maize [15], soybean [15], pea [11], sunflower [11], tomato [11], wheat [11, 12], rapeseed [12] and different plant cells [8-10, 13, 14] was observed. Notably, most of these studies only used qualitative methods such as Scanning Electron Microscopy (SEM), Transmission Electron Microscopy (TEM) and Raman spectroscopy [8-10, 13-15, 20, 22-25]. There are some distinct disadvantages when using qualitative methods to confirm the presence of CNTs in biological samples. For example, CNTs detection in plant tissues by SEM/TEM requires significant sample pretreatment and fixation, and minor variations in sample dissection can create significant experimental artifacts. Raman spectroscopic analysis can demonstrate CNTs accumulation in plants by detecting the relative CNT signal, but the method sensitivity is quite low. Irin et al. did not detect CNT Raman signals in alfalfa grown for 14 days in $1000 \mathrm{mg} / \mathrm{kg}$ MWCNT soil, although the presence of MWCNT was confirmed by thermal gravimetric analysis and microwave approaches [26]. Clearly, robust quantitative methods are needed in order to accurately characterize the toxicity, uptake, and translocation of CNTs in plants. 
Several quantitative approaches, including isotopic labeling [12], near infrared fluorescence [27], photoluminescence [28], thermogravimetry [29, 30] have been used with CNTs recently $[12,31,32]$. However, to date there has not been sufficient CNT accumulation data obtained to accurately describe the relationship between CNT content in plant tissues, CNT properties, and resulting biochemical/physiological effects. Once these relationships are defined, a mechanistic understanding of the governing processes will be more likely.

Small polar aromatic organic molecules (SPAOMs) occur either naturally (e.g. Lphenylalanine, 4-aminobenzoic acid) or from anthropogenic activity (e.g. nitrobenzene, phenols) and are ubiquitous in the environment. However, little is known about the effect of SPAOMs on CNTs fate in planted systems. There are limited but related studies focusing on accumulation of pesticides by plants in the presence of CNTs [33-35]. The results showed that pesticide uptake was generally reduced by CNTs [33-35]. Given the evidence for the potential toxicity of CNTs to animals $[8,16]$ and plants $[19,20,22,36-40]$, the effects of SPAOMs on CNT fate should be carefully studied. Our previous study showed that SPAOMs can promote CNTs dispersion and enhance material stability in solution as a function of organic co-solute water solubility [41]. In addition, due to their phytotoxicity [42, 43], SPAOMs could also indirectly impact CNTs accumulation in plants by affecting plant biochemical/physiological properties.

In this study, one model plant Arabidopsis thaliana, three crops, including Oryza sativa (rice), Zea mays (maize), and Glycine max (soybean), were selected for MWCNTs quantitative uptake study. Additionally, we further examined the physiological and biochemical responses of Arabidopsis under the co-contaminated environment. The representative SPAOMs included 1,4dinitrobezene (1,4DNB, water solubility Cs $69 \mathrm{mg} / \mathrm{L})$, 1,2-dinitrobenzene (1,2DNB, $133 \mathrm{mg} / \mathrm{L})$, 1,3-dinitrobenzene (1,3DNB $574.9 \mathrm{mg} / \mathrm{L})$, nitrobenzene (NB, $1936 \mathrm{mg} / \mathrm{L})$, 2,4-dichlorophenol (2,4DCP, $4600 \mathrm{mg} / \mathrm{L}, \mathrm{pKa}=7.90)$, 2-chlorophenol (2CP, $28500 \mathrm{mg} / \mathrm{L}, \mathrm{pKa}=8.44)$ and 4chlorophenol (4CP, $26300 \mathrm{mg} / \mathrm{L}, \mathrm{pKa}=9.38$ ) [44]. C-14 labeled MWCNTs were used to quantify the uptake and distribution of MWCNTs in plants. The specific objectives of the current study were to 1) quantitatively evaluate the distribution of MWCNTs in different plant tissues and 2) characterize the relationship between CNTs uptake, plant biochemical/physiological properties, and CNT properties in the presence of SPAOMs. The results of this study will provide important information for the accurate determination of risk associated with CNT exposure. 


\subsection{Chemicals and Reagents}

${ }^{14} \mathrm{C}$-labeled MWCNTs were synthesized by a modified chemical vapor deposition (CVD) and were treated with a 3:1 mixture of sulfuric to nitric acid as described in previous studies [45-

116 48]. The MWCNTs had a specific surface area of $111 \mathrm{~m}^{2} / \mathrm{g}$ and a specific radioactivity of 0.1

$117 \mathrm{mCi} / \mathrm{g}$. The surface oxygen content was $8.6 \%$ as measured by X-ray photoelectron spectroscopy 118 analysis [47]. A MWCNTs suspension was obtained by mixing $100 \mathrm{mg}$ MWCNTs into $1 \mathrm{~L}$ of 119 de-ionized water via ultrasonication (200 W; Cole-Parmer CV33) for $2 \mathrm{~h}$; the solution was then $120 \mathrm{kept}$ at $25 \pm 1{ }^{\circ} \mathrm{C}$ for $10 \mathrm{~h}$ before use. The initial concentration of MWCNTs was $74.1 \mathrm{mg} / \mathrm{L}$ by 121 using liquid scintillation counting (LSC; Benchman [Fullerton, CA] LS6500). Thermal 122 gravimetric and scanning electron microscopic analyses are provided in the Supporting 123 Information (Figure S1). The average MWCNT diameter was $36.5 \pm 12.7 \mathrm{~nm}(\mathrm{n}=80$, the 124 uncertainty indicates the standard deviation), and the average length was $350 \mathrm{~nm}(\mathrm{n}=836$; 125 Figure S1c).

126 Nitrobenzene was purchased from Acros Organics Co. Dinitrobenzenes (1,2DNB, 1,3DNB 127 and 1,4DNB) and chlorophenols (2,4DCP, 2CP and 4CP) were obtained from Sigma-Aldrich Co. 128 Murashige and Skoog (MS) basal medium with vitamins and sucrose were both from 129 PhytoTechnology Lab (Shawnee Mission, Kansas).

\section{$130 \quad 2.2$ Hydroponic Experiment}

131 Prior to the hydroponic experiment, Arabidopsis was grown in different concentrations $(0$, $1320.45,0.9,2.25$ and $4.5 \mathrm{mg} / \mathrm{L})$ of MWCNTs amended half-strength (1/2X) MS semisolid medium 133 (2.22 g MS basal medium with vitamins, $10 \mathrm{~g}$ sucrose in $1 \mathrm{~L}$ deionized water, $\mathrm{pH}$ 5.7) for 25 134 days under an environmentally controlled growth chamber (light period: 16/8 hrs; temperature: $13522 / 20{ }^{\circ} \mathrm{C}$, day/night) to determine the preferred concentration (based on fresh biomass) (Figure 136 1a). Briefly, Arabidopsis seeds were sterilized with ethanol (70\%, v/v) for $10 \mathrm{~min}$ and then twice 137 soaked in Clorox $(25 \%, \mathrm{v} / \mathrm{v})$ for $15 \mathrm{~min}$. The seeds were washed five times with autoclaved 138 deionized water before use [49]. A series of MWCNTs concentrations $(0,0.45,0.9,2.25$ and 4.5 $139 \mathrm{mg} / \mathrm{L}$ ) were prepared in 1/2X MS semisolid medium supplemented with $8 \mathrm{~g}$ phytoblend agar 140 (Caisson Laboratories, UT). Twenty-five sterilized seeds were placed on each dish and were 141 stratified at $4{ }^{\circ} \mathrm{C}$ for $24 \mathrm{~h}$ before transferred to the growth chamber (Percival Scientific, Perry, 142 IA). After seed germination, the Petri dishes were placed vertically in order to facilitate shoot 143 and root growth during an additional 25 days. At harvest, the total biomass in each treatment was 
used to select the MWCNTs concentration in the following experiment. The results showed that

$1452.25 \mathrm{mg} / \mathrm{L}$ MWCNT had no impact on Arabidopsis growth, whereas significantly lower biomass 146 was evident upon exposure to $4.50 \mathrm{mg} / \mathrm{L}$ (Figure S2). Hence, $2.25 \mathrm{mg} / \mathrm{L}$ MWCNT was chosen 147 for the subsequent hydroponic experiment. Given that our primary goal was to quantify 148 MWCNT uptake by and distribution in plants, although the MWCNT concentrations were high, 149 they were fit for purpose [50]. The hydroponic experimental design is shown in Figure $1 \mathrm{~b}$. 150 Arabidopsis was incubated in Petri dishes for 14 days and was then transferred to Hoagland's 151 solution (PhytoTechnology Laboratories, KS) in $250 \mathrm{~mL}$ beaker for 7 days to acclimatize the 152 new environment. Arabidopsis was then moved into $90 \mathrm{~mL}$ fresh Hoagland's solution amended 153 with $2.25 \mathrm{mg} / \mathrm{L}$ MWCNT suspension and $0.325 \mathrm{mM}$ SPAOMs for 24 hours exposure. The 154 reason we chose $0.325 \mathrm{mM}$ for SPAOMs is that they significantly affect MWCNTs dispersibility 155 [41]. At harvest, parameters (described below) including MWCNT uptake, pigment analysis, and 156 antioxidant enzyme activities were measured in each treatment. Each treatment was repeated at 157 least four times to ensure the reproducibility of the results.

158

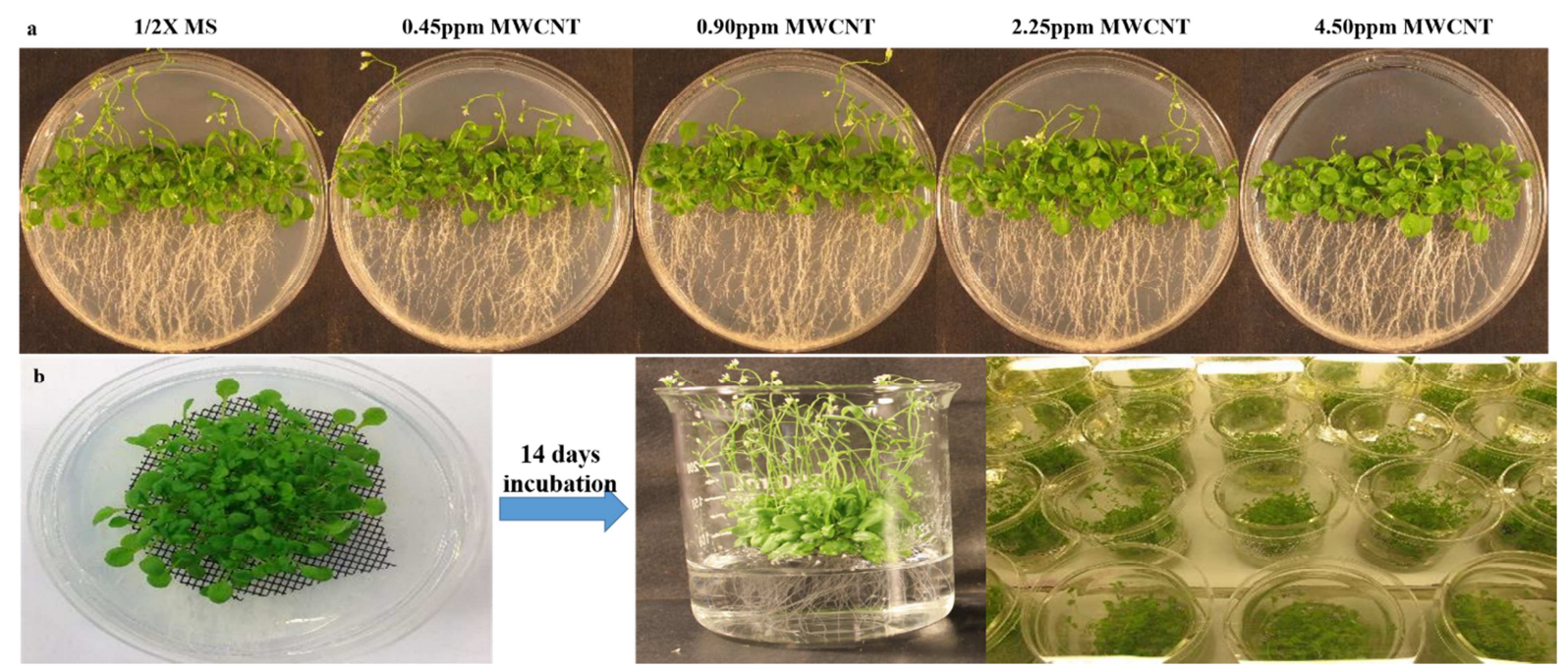

Fig. 1- Impact of MWCNTs on Arabidopsis germination and seedling growth. (a) Images of Arabidopsis treated with different concentrations of MWCNTs (b) Hydroponic experimental design.

159

For three crop plants, the seeds were germinated in vermiculite for 14 days. The seedlings 161 were then transferred to $1 / 2 \mathrm{X}$ Hoagland's solution amended test tube and allowed to acclimatize for 5 days. The identical concentration of MWCNTs $(2.25 \mathrm{mg} / \mathrm{L})$ was used in the uptake study. 
163 All three plants were exposed to the identical concentration of MWCNTs $(2.25 \mathrm{mg} / \mathrm{L})$ as used in

164 Arabidopsis exposure experiment for 1 day. At harvest, roots and shoots were separately rinsed 165 with deionized water three times, then fresh tissues were used for quantitative analysis of the 166 contents of MWCNTs using LSC.

\section{$167 \quad 2.3$ Quantitative Evaluation of MWCNTs in Plant Tissues}

168 Approximately $50 \mathrm{mg}$ plant tissues (root, sheath/stem and leaf) were used to measure 169 MWCNTs content. Roots were carefully washed by deionized water to remove the adsorbed 170 MWCNTs on root surface. A control experiment was applied to determine the adsorbed 171 MWCNTs on root surface by immersing the root into $2.25 \mathrm{mg} / \mathrm{L}$ MWCNTs solution for $1 \mathrm{~min}$. 172 The identical washing procedure was used to remove the adsorbed MWCNTs. The results 173 showed that no detectable MWCNTs were adsorbed on root surface. The plant tissue was then 174 grinded on an agate mortar and carefully transferred into $3 \mathrm{~mL}$ scintillation cocktail (Ultima gold 175 XR, Fisher Scientific, PA) for LSC. Preliminary experiments used a fixed amount of MWCNTs 176 with and without $50 \mathrm{mg}$ grinded plant tissues were analyzed by LSC to test for matrix effects, but 177 no significant difference was found (Figure S3). The background signal for LSC analysis is 29.3 $178 \pm 2.0$ DPM. The detection limit for LSC analysis of C-14 MWCNTs is $0.05 \mu \mathrm{g} / \mathrm{mL}$.

\section{$179 \quad 2.4$ Stability of MWCNTs Suspension}

180 A particle size analysis (Nanosizer, 90Plus, Brookhaven) was performed to determine and 181 compare the stabilization of aqueous phase MWCNTs $(2.25 \mathrm{mg} / \mathrm{L})$ in the presence of $0.325 \mathrm{mM}$ 182 SPAOMs. The morphology of suspended MWCNTs was investigated using transmission 183 electron microscopy (TEM, H-7650, Hitachi, Japan). MWCNTs suspensions with and without 184 SPAOMs were diluted in order to minimize background solution influence and were fixed on a 185 nickel grid for observation under TEM. The $\mathrm{pH}$ value in MWCNTs suspension with the presence 186 of SPAOMs was measured by a pH meter (XL 200, Fisher Scientific accumet).

\section{$187 \quad 2.5$ Physiological and Biochemical Assays}

\subsubsection{Transpiration and Pigment Measurement}

The transpiration of each Arabidopsis treatment was calculated by the mass difference 190 between the initial and final beaker system after 24 hours. Arabidopsis shoots were harvested 191 and grounded in liquid nitrogen for anthocyanin extraction. Fifty mg of grounded tissues were 192 mixed with $1 \mathrm{~mL}$ methanol amended with $1 \%(\mathrm{v} / \mathrm{v}) \mathrm{HCl}$ and were then incubated in the dark at 4 $193{ }^{\circ} \mathrm{C}$ overnight. A mixture containing $500 \mu \mathrm{L}$ of chloroform and $500 \mu \mathrm{L}$ of $\mathrm{DI}_{2} \mathrm{H}_{2} \mathrm{O}$ was used to 
separate anthocyanin from chlorophyll. The supernatant absorbance was measured at $530 \mathrm{~nm}$ and $657 \mathrm{~nm}$ by UV-Vis spectrophotometer (Agilent 8453). The final concentration of anthocyanin was determined by using $\mathrm{A}_{530}-1 / 4 \mathrm{~A}_{657}$. Chorophyll was measured as described by Lichtenthaler et al. with revision [51]. Briefly, $50 \mathrm{mg}$ of fresh leaves were collected and cut into pieces (less than $1 \mathrm{~cm}$ ). A volume of $10 \mathrm{~mL} \mathrm{95 \%} \mathrm{ethanol} \mathrm{was} \mathrm{used} \mathrm{to} \mathrm{extract} \mathrm{the} \mathrm{total} \mathrm{chlorophyll.} \mathrm{All}$ samples were kept in the dark for 3 days to avoid chlorophyll degradation. The absorbance was measured at $664.2 \mathrm{~nm}$ and $648.6 \mathrm{~nm}$ by UV-Vis spectrophotometer. Chlorophyll a, chlorophyll b and total chlorophyll were calculated by the following equations: Chla=13.36 $\mathrm{A}_{664.2}-5.19 \mathrm{~A}_{648.6}$, Chlb $=27.43 \mathrm{~A}_{648.6}-8.12 \mathrm{~A}_{664.2}$ and Total chlorophyll=Chla + Chlb.

\subsubsection{Total Protein Measurement}

The Bradford reagent (purchased from Sigma Aldrich) was used to measure the total protein content in plant tissues [52]. A sample of $50 \mathrm{mg}$ of Arabidopsis seedlings (shoots and roots) was extracted in $2 \mathrm{~mL}$ of $10 \mathrm{mM}$ Tris- $\mathrm{HCl}$ ( $\mathrm{pH} \mathrm{7.2)} \mathrm{solution.} \mathrm{The} \mathrm{mixture} \mathrm{was} \mathrm{then} \mathrm{centrifuged} \mathrm{at}$ $4000 \mathrm{rpm}$ for $20 \mathrm{~min}$ at $4{ }^{\circ} \mathrm{C}$. One hundred $\mu \mathrm{L}$ of supernatant was used to react with $1000 \mu \mathrm{L}$ of Bradford reagent for $15 \mathrm{~min}$ at ambient temperature, and then the absorbance was measured at $595 \mathrm{~nm}$ by UV-Vis spectrophotometer.

\subsubsection{Antioxidative Enzyme Measurement}

Catalase (CAT) in Arabidopsis seedlings (shoots and roots) was extracted in $25 \mathrm{mM}$ $\mathrm{KH}_{2} \mathrm{PO}_{4}$ with $\mathrm{pH}$ 7.4. Decreased absorbance in the reaction that contained $100 \mu \mathrm{L}$ of supernatant and $1900 \mu \mathrm{L}$ of reaction buffer $\left(10 \mathrm{mM} \mathrm{H}_{2} \mathrm{O}_{2}\right)$ was recorded at $240 \mathrm{~nm}$ for $3 \mathrm{~min}$. The $\mathrm{H}_{2} \mathrm{O}_{2}$ extinction coefficient was $23.148 \mathrm{mM}^{-1} \mathrm{~cm}^{-1}$ [53]. Ascorbate peroxidase (APX) was extracted in $100 \mathrm{mM}$ phosphate buffer ( $\mathrm{pH} 7.0$ ) containing $0.1 \mathrm{mM}$ EDTA, $0.1 \mathrm{mM}$ ascorbate and $2 \% \beta$ mercaptoethanol. The reaction buffer contained $50 \mathrm{mM}$ phosphate buffer $(\mathrm{pH} 7.0)$ and $0.6 \mathrm{mM}$ ascorbic acid. The total $2 \mathrm{~mL}$ reaction system contained $100 \mu \mathrm{L}$ of enzyme extract and $1900 \mu \mathrm{L}$ of reaction buffer. Decreased absorbance was monitored at $290 \mathrm{~nm}$ for $3 \mathrm{~min}$ after initiating the reaction with $10 \% \mathrm{H}_{2} \mathrm{O}_{2}$ [54]. Superoxide dismutase (SOD) was extracted in $50 \mathrm{mM}$ phosphate ( $\mathrm{pH} 7.8$ ) containing $0.1 \%(\mathrm{w} / \mathrm{v})$ ascorbate, $0.1 \%(\mathrm{w} / \mathrm{v})$ bovine serum albumin (BSA), and $0.05 \%$ $(\mathrm{w} / \mathrm{v}) \beta$-mercaptoethanol. Nitroblue tetrazolium (NBT) was used to indirectly determine SOD activities. Briefly, $100 \mu \mathrm{L}$ of enzyme extract and $1900 \mu \mathrm{L}$ of $50 \mathrm{mM}$ phosphate buffer $(\mathrm{pH} 7.8)$ containing $9.9 \mathrm{mM}$ L-methionine, $57 \mu \mathrm{M}$ NBT, $0.0044 \%$ (w/v) riboflavin and $0.025 \%(\mathrm{w} / \mathrm{v})$ 
Triton X-100 were mixed in cuvette and placed at $37{ }^{\circ} \mathrm{C}$ for 20 min. Reduction of NBT was recorded at $560 \mathrm{~nm}$ [54].

\subsection{Statistical Analysis}

Replicate Arabidopsis root, stem and leaf tissues were separated and analyzed in quadruplicate for each treatment. Data were statistically analyzed using SPSS 18.0. The leastsignificant differences (LSDs) were used to determine difference of statistical significance among the different assays. Stepwise multiple linear regression analysis was conducted using SPSS. Q-Q plots and Kolmogorov-Smirnof test were applied to evaluate data normality [44, 48]. The applicability domain of stepwise multiple linear regression results were verified by the leverage approach using the plot of standardized residuals versus leverages (hat diagonals), i.e. the Williams plot $[44,48]$. The robustness of stepwise multiple linear regression equations are estimated through an initial two step development: 1) splitting the data into training and validation sets and 2) validating the data via internal and external certification (Supporting Information Stepwise multiple linear regression part) [44, 48].

\section{Results and Discussion}

\subsection{MWCNTs Uptake by Plants}

The ${ }^{14} \mathrm{C}$-labled MWCNTs content in different plant tissues ranged from $0.53 \pm 0.31$ (in maize sheath) to $76.6 \pm 6.1$ (in soybean root) $\mathrm{mg} / \mathrm{kg}$, thus demonstrating that MWCNTs could not only enter the roots, but it could also effectively translocate to the aboveground tissues (Figure 2). The hydrodynamic radius of $2.25 \mathrm{mg} / \mathrm{L}$ MWCNTs in Hoagland's solution was measured at $248.12 \pm 14.24 \mathrm{~nm}$; given that the pore diameters of plant cell walls range from 5 to $20 \mathrm{~nm}$, the uptake of MWCNTs likely depends on the enlargement of pores or the induction of physical damage resulting in compromised cell wall integrity [55]. The MWCNTs content in rice root was approximately $22.5 \mathrm{mg} / \mathrm{kg}$, which was more than 2-fold that of the sheath (Figure $2 \mathrm{~F}$ ). MWCNTs content in rice leaf decreased to one tenth of the root. Both maize and soybean accumulated high amounts of MWCNTs in their roots as compared with the aboveground tissues (Figure $2 \mathrm{G}$ and $2 \mathrm{H}$ ), but no significant differences were evident between the stem/sheath and leaf tissues. The MWCNT content in Arabidopsis leaf $(13.0 \pm 0.9 \mathrm{mg} / \mathrm{kg})$ was the highest among four plants, which was more than 10 -fold that of the stem $(1.0 \pm 0.3 \mathrm{mg} / \mathrm{kg})$. Comparing the four scenarios of uptake in Figure 2, the MWCNTs content in soybean root was 1.4, 3.4 and 2.4-fold higher than Arabidopsis, rice and maize, respectively. However, the MWCNTs translocation 
factor (TF: ratio of average MWCNTs content in leaves and stems versus in roots) indicated that rice could translocate more MWCNTs $(\mathrm{TF}=0.582)$ to the aboveground tissues (leaf and sheath) as compared to Arabidopsis, maize and soybean, whose TF was 0.2620, 0.054 and 0.141, respectively (Table S4). Our TF values ranging from 0.054-0.582 in four plants, which are higher than the values in wheat and rapeseed as reported by Larue et al. [12]. This difference might be attributed to the different plant species used and the different sizes of MWCNTs. In our study, the length of MWCNTs was $350 \mathrm{~nm}$ compared to $2.65 \pm 1.55 \mu \mathrm{m}$ and $2.90 \pm 1.55 \mu \mathrm{m}$ in the study by Larue et al. [12].
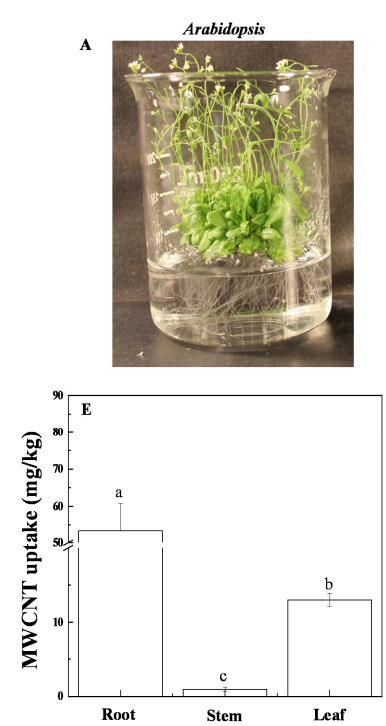
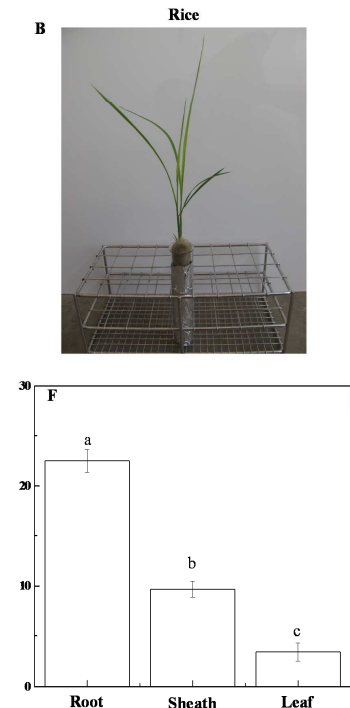
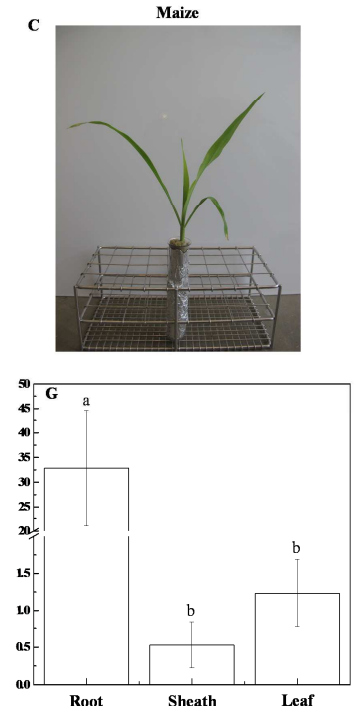
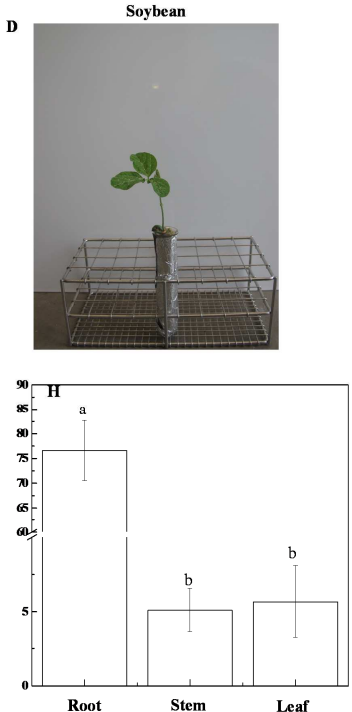

Fig. 2- MWCNTs distribution in Arabidopsis, rice, maize and soybean. (A-D) Phenotypic images of each plant species; (E-H) MWCNTs content different plant tissues. Values in the same plant followed by the same letter $(\mathrm{a}-\mathrm{c})$ were not significantly different at $p<0.05$. Error bar represents standard error of four replicates.

\subsection{MWCNTs Uptake in the Presence of SPAOMs by Arabidopsis}

The ${ }^{14} \mathrm{C}$-labled MWCNTs content in Arabidopsis tissues across all SPAOMs treatments ranged from 0.22 to $79.68 \mathrm{mg} / \mathrm{kg}$ (Figure 3). The accumulation of MWCNTs varied from Arabidopsis roots to shoots, with the pattern of distributions in all treatments following the sequence: root $>$ leaf $>$ stem (Figure 2). These findings agree with previous studies on CNTs accumulation in maize [15], soybean [15], wheat [12] and rapeseed [12]. In our work (Figure $1 b$ ), the roots were the only tissue in direct contact with the MWCNTs suspension, resulting in high nanotube concentrations (CK treatment of Figure 3a). The stems accumulated the lowest 
amount of MWCNTs (CK treatment of Figure 3c), indicating that passage through the stems to the leaves is likely a rapid progress [15]. Importantly, the uptake efficiency was significantly and distinctly altered by co-exposure to different SPAOMs (Figure 3). 2,4DCP reduced MWCNTs uptake by stems and leaves to the greatest extent, whereas 1,4DNB inhibited root accumulation most significantly (Figure 3). The TF value showed that the MWCNT uptake amount in the presence of 2,4DCP is the lowest (Figure 3), which might be attributed to the plant 293 biochemical/physiological properties, and CNT properties changes induced by SPAOMs.
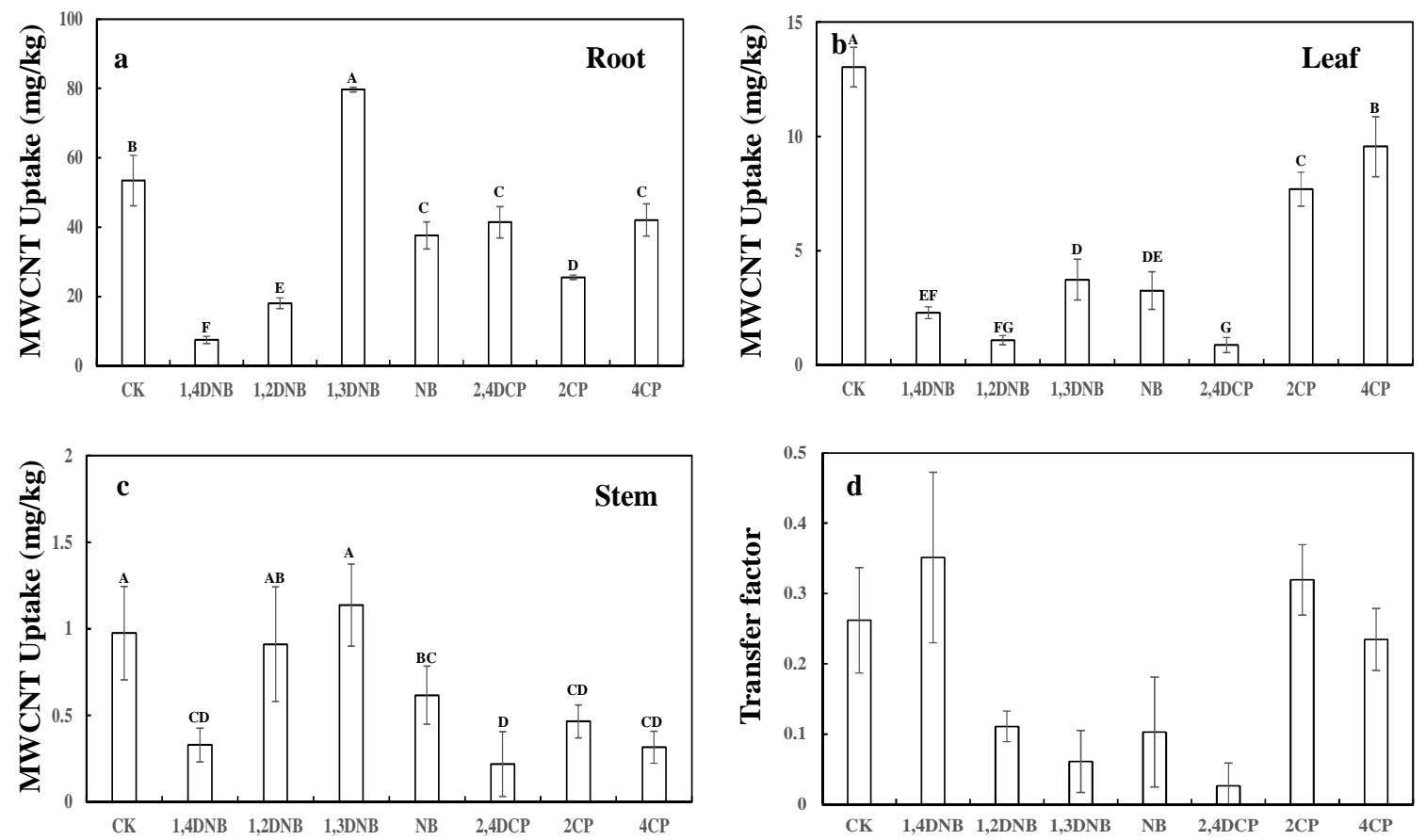

Fig. 3- MWCNT distribution in Arabidopsis in the presence of SPAOMs. a) MWCNT content in roots; b) MWCNT content in leaves; c) MWCNT content in stems. Error bars represent standard error of four replicates. Values among different SPAOM treatments followed by the same letter (A-D) were not significantly different at $p<0.05$. d) Translocation factor (MWCNT content in leaves and stems versus MWCNT in roots) of MWCNT in Arabidopsis. Error bars represent standard error of four replicates.

\subsection{Toxicity Effects on MWCNTs Accumulation}

Current reports on the phytotoxicity of MWCNTs are somewhat contradictory $[1,56]$. CNTs induced positive effects on tomato flowering [57] fruiting [57] and water channel protein production [58], spinach photosynthetic activity [59] as well as wheat and maize root growth [21, $39,60]$. Conversely, others have observed inhibited root and shoot growth [20, 36, 39], increased reactive oxygen species [37, 38], and chromosomal aberrations [19] upon CNT exposure. Many 
factors can affect plant growth in the presence of MWCNTs, including nanotube physical/chemical properties, plant species, and experimental conditions (exposure time, substrate, growth conditions). In our study, the presence of MWCNTs $(2.25 \mathrm{mg} / \mathrm{L})$ had no impact on measured physiological parameters, including transpiration, anthocyanin contents and chlorophyll contents (CK treatment of Figures 4a-d). In the co-exposure treatments with SPAOMs, MWCNTs either increased or had no impact on the anthocyanin content as compared with the respective controls (SPAOMs alone treatment) (Figure 4b). For example, the anthocyanin contents in both co-exposure treatments of 1,2 DNB+MWCNTs and $4 \mathrm{CP}+\mathrm{MWCNTs}$ were 2-fold greater than the respective controls. No differences were evident in most of the remaining treatments, with the exception of 1,4 DNB+MWCNTs, where significantly lower anthocyanin content was found relative to the 1,4 DNB alone treatment (Figure $4 \mathrm{~b}$ ). During the 24 hours exposure, the total chlorophyll content did not change upon exposure to MWCNTs, SPAOMs, and SPAOMs + MWCNTs (Figure 4c and d). Notably, SPAOMs exposure reduced the total protein content in Arabidopsis seedlings by approximately $50 \%$ as compared to controls. In the co-exposure treatments, MWCNTs presence restored the protein content back to the level of the MWCNTs control group, suggesting that nanotubes could alleviate some of the SPAOMs-induced toxicity and help to stabilize plant protein content, although the total protein content was also reduced in the MWCNT alone treatment as compared with the unexposed control. The possible explanation might be that the CNTs can decrease bioavailability of the organic compounds, due to its high adsorption affinities for polar and hydrophobic compounds. Previous studies also agreed that MWCNT could generally reduce pesticides' uptake by plants [33-35].

Antioxidant enzyme activities, including APX, CAT, and SOD, were significantly induced, particularly in the SPAOMs alone treatments (Figures $4 \mathrm{e}, \mathrm{f}$ and $\mathrm{g}$ ). For example, the presence of 1,3 DNB, NB, and 2,4 DCP elevated APX activities by approximately 7, 6, and 7-fold, respectively. Similarly, CAT and SOD activities were also significantly higher among these three exposures as compared to the controls and the remainder of the treatments (Figure 4f). Interestingly, the addition of MWCNTs decreased (in some cases e.g. 1,3DNB, NB, 2,4DCP significantly decreased) the antioxidant enzyme activities relative to its respective SPAOMs alone treatment. The results were consistent with the physiological data, where MWCNTs significantly reduced the phytotoxicity of SPAOMs. In a previous study, significant elevation of 
antioxidant enzyme activity indicated that CNTs could cause ROS overproduction and subsequently result in damages to biological molecules such as lipids, proteins and DNA [49].

334 Conversely, our results suggested that the presence of MWCNTs could significantly alleviate 335 SPAOMs toxicity to Arabidopsis seedlings. In addition, the concentration of nutrients in $1 / 2 \mathrm{X}$ 336 Hoagland's solution with/without MWCNTs was measured (Table S2). The levels of several 337 nutrients (B, Ca, K, Mg, Mn, S) were significantly higher in the pure Hoagland's solution than in 338 the MWCNTs amended solution; the exception being $\mathrm{Na}$ and $\mathrm{P}$, both of which did not show 339 difference between the two treatments. This is probably ascribed to the sorption of nutrients by 340 MWCNTs. Across all eight parameters in Figure 4, changes in antioxidant enzyme activities are 341 more sensitive than the physiological parameters across all treatments after 24 hours exposure. 342 Reductions in antioxidant enzyme activities in co-exposure treatments suggested that the 343 presences of MWCNTs could significantly counteract SPAOMs toxicity to Arabidopsis seedlings, subsequently restoring antioxidant enzyme activity back to the nanotube control levels. The mechanisms driving these nanotube-contaminant-plant interactions are unknown but are the topic of ongoing investigation. The activities of antioxidant enzymes, including APX, CAT, and SOD, can scavenge ROS in form of $\mathrm{H}_{2} \mathrm{O}_{2}$ and $\mathrm{O}_{2}{ }^{--}$and break these molecules down to $\mathrm{H}_{2} \mathrm{O}$ or $\mathrm{O}_{2}$. Elevated activities of three antioxidant enzymes indicated that the presence of SPAOMs could increase the ROS levels in plants. For example, APX activity in 2,4-DCP treated Arabidopsis was 6.9-fold higher relative to the control group (Figure 4f); similarly, CAT and SOD activities were 17.5-fold and 9.8-fold that of the control, respectively (Figures $4 \mathrm{~g}$ and $\mathrm{h}$ ). Although the other SPAOMs could also increase the activities of three antioxidant enzymes in Arabidopsis, 2,4-DCP seems to be the most phytotoxic in terms of antioxidant response. When comparing the TF of MWCNT in Arabidopsis, the presence of 2,4-DCP significantly decreased MWCNT translocation (Figure 3d), suggesting that plant may down regulate the activity of some specific transporters in the cell membrane in response to organic contaminant exposure. The presence of MWCNTs has been shown to have the opposite effect, inducing up regulation of a water channel protein (LeAqp2) in tomato roots, and subsequently enhance the seed germination and plant growth [25]. Under the stress conditions, SPAOMs might modulate the stress-related genes (aquaporin genes), effectively decreasing the likelihood of plants to accumulate MWCNTs. 

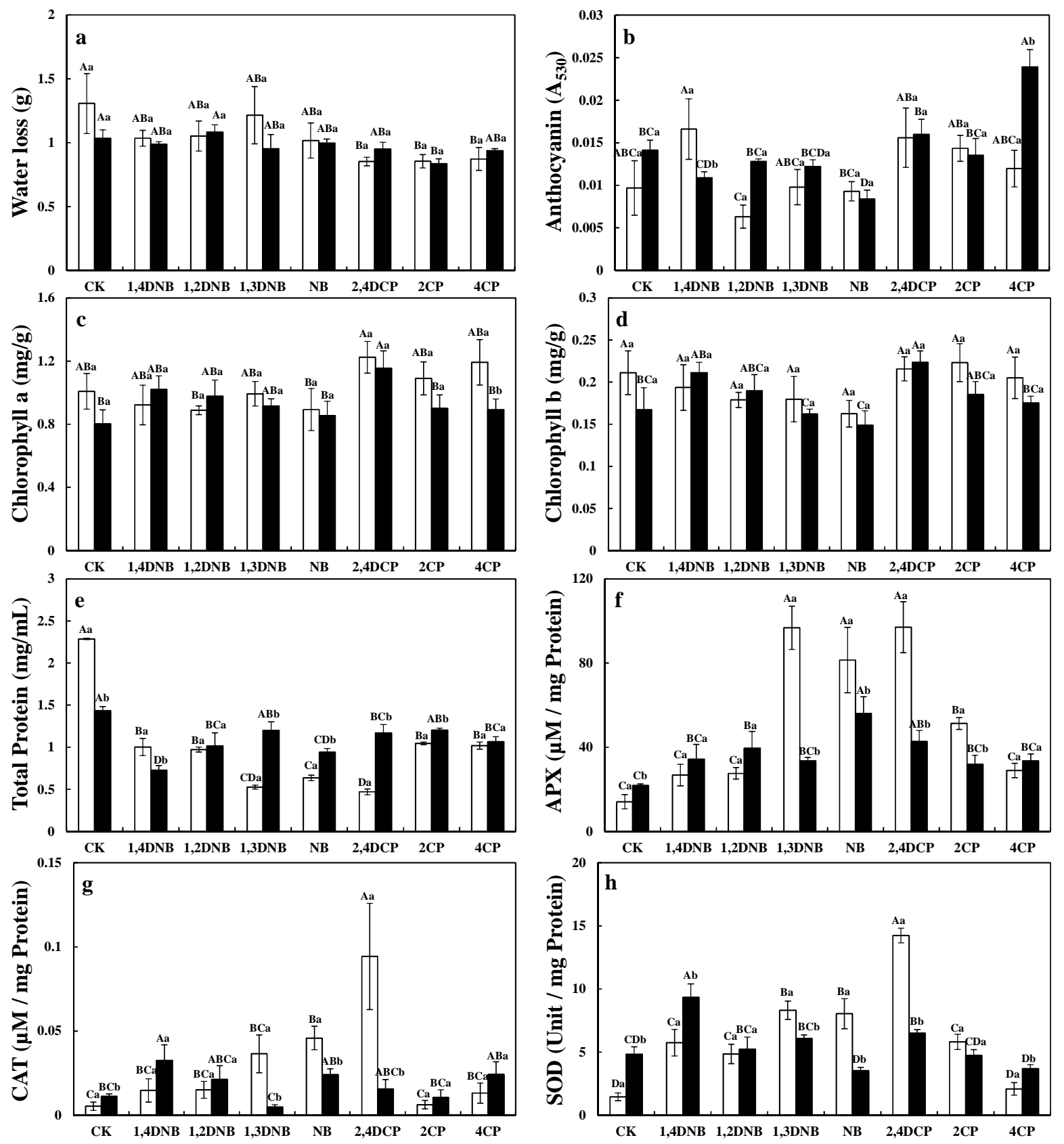

Fig. 4- Inhibition of Arabidopsis by SPAOMs with (black bar) and without (white bar) MWCNTs addition at both physiological and biochemical levels after 24 hrs exposure. a) Transpiration; b) Anthocyanin; c) Chlorophyll a; d) chlorophyll b; e) Total Protein; f) Ascorbate peroxidases; g) Catalase; h) Superoxide dismutases. Error bars represent standard error of four replicates. Values among different SPAOM treatments followed by the same letter (A-D) were not significantly different at $p<0.05$. Values in the same SPAOM treatments with and without MWCNT followed by the same letter $(a-b)$ were not significantly different at $p<0.05$. 
b

c

\subsection{Stability Effects on MWCNTs Accumulation.}
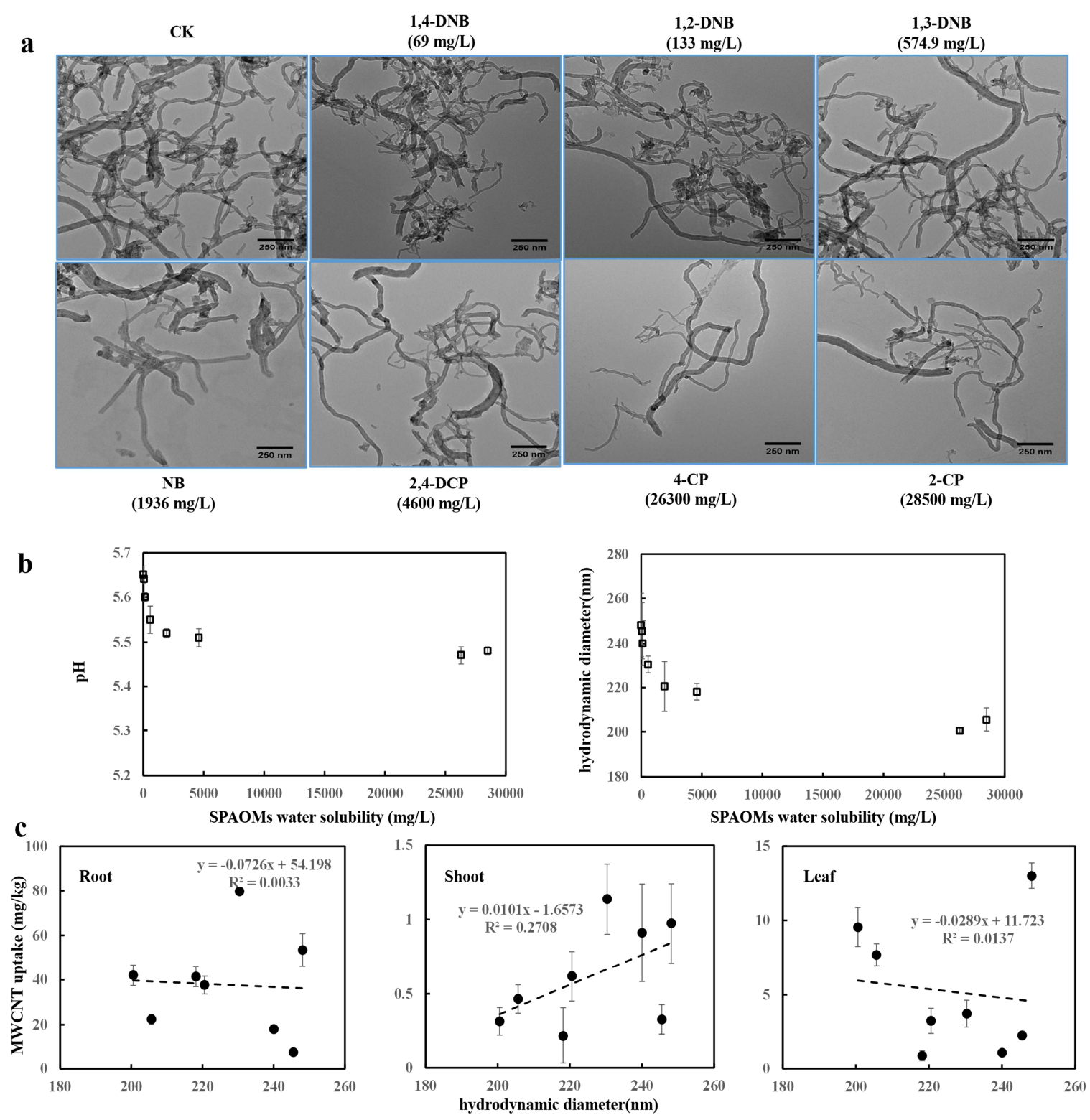

Particle and aggregate sizes have been shown to influence the uptake of MWCNTs by plants $[13,15]$. Our previous study demonstrated that SPAOMs can disperse MWCNTs and that this dispersibility correlated well with water solubility [41]. Here, TEM images confirmed that dispersibility of MWCNTs increased with increasing SPAOM water solubility (Figure 5a).

Fig. 5- Effect of MWCNTs stability on their accumulation. a) TEM images of MWCNTs suspensions in the presence of different water solubility SPAOMs; b) suspension $\mathrm{pH}$ value and particle size in the presence of different water solubility SPAOMs; c) Quantitative correlation between MWCNT uptake and hydrodynamic diameter of MWCNTs in different plant tissues. Error bar represents standard error of four replicates. 
Specifically, increasing SPAOMs solubility resulted in a decrease of solution $\mathrm{pH}$ and of MWCNTs hydrodynamic diameter (Figure 5b). In the experiment pH range (5.4-5.7), all applied chemicals are in their molecular forms. Thus, the decrease of solution $\mathrm{pH}$ and MWCNTs hydrodynamic diameter with increasing SPAOMs solubility probably suggests a possible dispersion mechanism. The adsorbed SPAOMs likely facilitated hydrophilic moieties' (e.g. - OH, $-\mathrm{COOH}$ ), which were initially obstructed in MWCNTs bundles and aggregates, interactions with the aqueous phase. The exposed hydrophilic moieties could then release $\mathrm{H}^{+}$and decrease the $\mathrm{pH}$ of the solution. The correlation between MWCNTs hydrodynamic diameter and uptake by the plants was evaluated (Figure 5c). Although the accumulation in root and leaf showed negative relationship (-0.0726 and -0.0289 , respectively) between MWCNTs hydrodynamic diameter and nanotube uptake, the correlation was not statistically significant. Thus, our results imply that MWCNTs hydrodynamic diameter does not significantly affect MWCNTs uptake by Arabidopsis.

\subsection{Stepwise Multiple Linear Regression Study}

It was difficult to find a relationship between a single plant biochemical/physiological property or CNT property and the MWCNTs uptake in different tissues, as indicated by low correlation coefficients $\mathrm{R}^{2}$ (Figure 5c and Figure S4). Thus, the correlation of MWCNTs uptake amount in root, stem and leaf tissue with plant biochemical/physiological properties and CNT properties was further analyzed by stepwise multiple linear regression analysis of the [U, WL, Ant, Chla, Chlb, TP, APX, CAT, SOD, HD] matrix. This yielded the following equations:

$$
\begin{gathered}
\mathrm{U}_{\text {root }}=(-1776.922 \pm 706.266) \mathrm{CAT}+(69.944 \pm 14.134) \quad \mathrm{R}^{2}=0.513 \\
U_{\text {leaf }}=(-0.441 \pm 0.085) \mathrm{APX}+(-1.292 \pm 0.373) \mathrm{SOD}+(28.097 \pm 3.890) \mathrm{R}^{2}=0.877
\end{gathered}
$$

where $\mathrm{U}$ represents the uptake amount in plant tissues $(\mathrm{mg} / \mathrm{kg})$; WL is the amount of water loss caused by transpiration (g); Ant indicates anthocyanin absorbance at $530 \mathrm{~nm}$; Chla and Chlb are chlorophyll a and chlorophyll b content, respectively $(\mathrm{mg} / \mathrm{g})$; TP is the total protein content $(\mathrm{mg} / \mathrm{mL})$; HD represents CNT hydrodynamic diameter $(\mathrm{nm})$. Analysis of variance results suggests that the regression equation has statistical significance (Table S4). The predicted versus measured $U$ values of the training set and validation set 1 and 2 are close to the $1: 1$ line, indicating the robustness of Eqns. (1) and (2) (Figure 6a). The applicability domain of the regression models was verified using a William plot (Figure 6b). All training and validation sets 
are within the domain, demonstrating that there are no outliers and that the predictive capacity of the models is reliable. The negative correlations between $U_{\text {root }}$ and CAT, between $U_{\text {leaf }}$ and APX and between $U_{\text {leaf }}$ and SOD further confirmed that the presence of SPAOMs could severely inhibit MWCNTs uptake in Arabidopsis. Unfortunately, we were unable to describe CNTs accumulation in the stems, which is likely the result of the rapid movement of MWCNTs through the stems to the leaves [15]. Our regression model of CNT accumulation in root and leaf directly points out that the phytotoxicity of SPAOMs could significantly impact CNTs accumulation in plants by affecting plant biochemical/physiological properties.

414

415
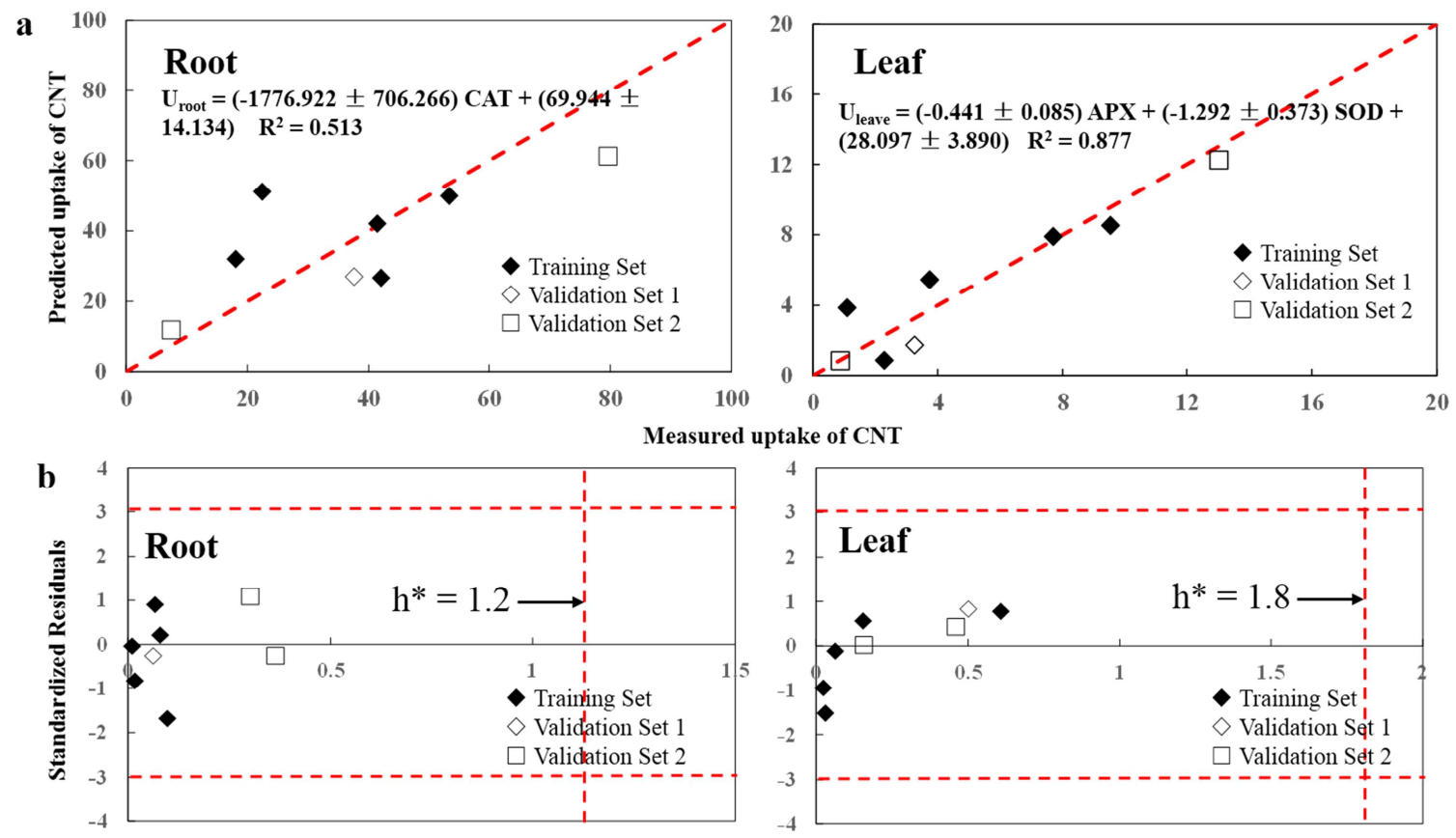

Fig. 6- (a) Predicted versus measured uptake amount of MWCNTs in roots and leaves. The dash line represents the 1:1 line. (b) The Williams plot for verifying the applicability domain of the model. This figure shows no outliers of training and validation data and that the 416 predictability of the model is reliable.

\section{7}

418

419

420

\section{Summary}

The successful evaluation of nanotube uptake by Arabidopsis, rice, maize and soybean demonstrates that radioactivity measurement is a feasible method for quantitative detection of MWCNTs in plant tissues. Additionally, this study revealed the potential and quantitative 
relationships between the stability and uptake of MWCNTs and the toxicity of SPAOMs using stepwise multiple linear regression model. Further study in the field of plant and carbon nanotube interactions is clearly necessary to solve the questions regarding the underlying uptake mechanisms from the molecular aspect, whether the differences of the uptake patterns are plant species-specific, whether MWCNT properties significantly influence uptake. Given the results from our present study, MWCNT interactions with biota and co-existing contaminants are strikingly complicated and have significant implications for the prediction of exposure to and risk from carbon-based nanomaterials in the environment.

\section{Acknowledgements}

We thank Dr. Elijah J. Petersen from National Institute of Standards and Technology for providing ${ }^{14} \mathrm{C}$-labled MWCNTs used in this study. This work was in part supported by Hundreds Talents Program of Chinese Academy of Sciences awarded to Q.Z. (2014-2019), CAS Pioneer Hundred Talents Program awarded to X.-J.Z. (2015-2020), Youth Innovation Promotion Association CAS awarded to S.-Y.Z. (2017-2020), Open Foundation of State Key Laboratory of Environmental Criteria and Risk Assessment, Chinese Research Academy of Environmental Sciences (SKLECRA2015OFP10), USDA-NIFA (2011-67006-30181) and USDA-NIFA Hatch program (MAS 00475).

\section{REFERENCES}

[1] Sarma SJ, Bhattacharya, I, Brar SK, Tyagi RD, Surampalli RY. Carbon nanotubebioaccumulation and recent advances in environmental monitoring. Crit Rev Environ Sci Technol 2015;45:905-38. [2] MacKenzie KJ, See CH, Dunens OM, Harris AT. Do single-walled carbon nanotubes occur naturally? Nat Nanotechnol 2008;3:310. 
[3] Kumar CSSR. Nanotechnologies for the life sciences. Weinheim; 2006.

450 [4] Kawasaki S, Shinoda M, Shimada T, Okino F, Touhara H. Single-walled carbon nanotubes 451 grown on natural minerals. Carbon 2006;44:2139-41.

452 [5] Iijima S. Helical microtubules of graphitic carbon. Nature 1991;354:56-8.

453 [6] Gottschalk F, Sonderer T, Scholz RW, Nowack B. Modeled environmental concentrations of 454 engineered nanomaterials ( $\mathrm{TiO}_{2}, \mathrm{ZnO}, \mathrm{Ag}$, CNT, Fullerenes) for different regions. Environ Sci 455 Technol 2009;43:9216-22.

456 [7] Petersen EJ, Pinto RA, Landrum PF, Weber WJ. Influence of carbon nanotubes on pyrene 457 bioaccumulation from contaminated soils by earthworms. Environ Sci Technol 2009;43:4181-7. 458 [8] Porter AE, Gass M, Muller K, Skepper JN, Midgley PA, Welland M. Direct imaging of 459 single-walled carbon nanotubes in cells. Nat Nanotechnol 2007;2:713-7.

460 [9] Liu QL, Chen B, Wang QL, Shi XL, Xiao ZY, Lin JX, et al. Carbon nanotubes as molecular 461 transporters for walled plant cells. Nano Lett 2009;9(3):1007-10.

462 [10] Chen R, Ratnikova TA, Stone MB, Lin S, Lard M, Huang G, et al. Differential uptake of 463 carbon nanoparticles by plant and mammalian cells. Small 2010;6(5):612-7.

464 [11] Cifuentes Z, Custardoy L, de la Fuente JM, Marquina C, Ibarra MR, Rubiales D, et al. 465 Absorption and translocation to the aerial part of magnetic carbon-coated nanoparticles 466 through the root of different crop plants. J Nanobiotechnol 2010;8:8.

467 [12] Larue C, Pinault M, Czarny B, Georgin D, Jaillard D, Bendiab N, et al. Quantitative 468 evaluation of multi-walled carbon nanotube uptake in wheat and rapeseed. J Hazard Mater 2012; 469 227:155-63.

470 [13] Serag MF, Kaji N, Gaillard C, Okamoto Y, Terasaka K, Jabasini M, et al. Trafficking and 471 subcellular localization of multiwalled carbon nanotubes in plant cells. ACS Nano $472 \quad 2011 ; 5(1): 493-9$.

473 [14] Baoukina S, Monticelli L, Tieleman DP. Interaction of pristine and functionalized carbon 474 nanotubes with lipid membranes. J Phys Chem B 2013;117(40):12113-23.

475 [15] Zhai GS, Gutowski SM, Walters KS, Yan B, Schnoor JL. Charge, size, and cellular 476 selectivity for multiwall carbon nanotubes by Maize and Soybean. Environ Sci Technol $477 \quad 2015 ; 49(12): 7380-90$.

478 [16] Petersen EJ, Henry TB. Methodological considerations for testing the ecotoxicity of carbon 479 nanotubes and fullerenes: Review. Environ Toxicol Chem 2012;31(1):60-72. 
480

481

482

483

484

485

486

487

488

489

490

491

492

493

494

495

496

497

498

499

500

501

502

503

504

505

506

507

508

509

510

511

[17] Maynard AD, Baron PA, Foley M, Shvedova AA, Kisin ER, Castranova. Exposure to carbon nanotube material: Aerosol release during the handling of unrefined single-walled carbon nanotube material. J Toxicol Environ Heal A 2004;67(1):87-107.

[18] Donaldson K, Aitken R, Tran L, Stone V, Duffin R, Forrest G, et al. Carbon nanotubes: A review of their properties in relation to pulmonary toxicology and workplace safety. Toxicol Sci 2006;92(1):5-22.

[19] Ghosh M, Chakraborty A, Bandyopadhyay M, Mukherjee A. Multi-walled carbon nanotubes (MWCNT): Induction of DNA damage in plant and mammalian cells. J Hazard Mater 2011;197:327-36.

[20] Canas JE, Long MQ, Nations S, Vadan R, Dai L, Luo MX, et al. Effects of functionalized and nonfunctionalized single-walled carbon nanotubes on root elongation of select crop species. Environ Toxicol Chem 2008;27(9):1922-31.

[21] Miralles P, Johnson E, Church TL, Harris AT. Multiwalled carbon nanotubes in alfalfa and wheat: toxicology and uptake. J R Soc Interface 2012;9(77):3514-27.

[22] Lin SJ, Reppert J, Hu Q, Hudson JS, Reid ML, Ratnikova TA, et al. Uptake, translocation, and transmission of carbon nanomaterials in rice plants. Small 2009;5(10):1128-32.

[23] Khodakovskaya M, Dervishi E, Mahmood M, Xu Y, Li ZR, Watanabe F, et al. Carbon nanotubes are able to penetrate plant seed coat and dramatically affect seed germination and plant growth (Retracted article. See vol. 6, pg. 7541, 2012). ACS Nano 2009;3(10):3221-7. [24] Khodakovskaya MV, de Silva K, Biris AS, Dervishi E, Villagarcia H. Carbon nanotubes induce growth enhancement of tobacco cells. ACS Nano 2012;6(3):2128-35.

[25] Khodakovskaya MV, de Silva K, Nedosekin DA, Dervishi E, Biris AS, Shashkov EV, et al. Complex genetic, photothermal, and photoacoustic analysis of nanoparticle-plant interactions. Proc Natl Acad Sci 2011;108(3):1028-33.

[26] Irin F, Shrestha B, Canas JE, Saed MA, Green MJ. Detection of carbon nanotubes in biological samples through microwave-induced heating. Carbon 2012;50(12):4441-9.

[27] Bisesi JH, Merten J, Liu K, Parks AN, Afrooz A, Glenn JB, et al. Tracking and quantification of single-walled carbon nanotubes in fish using near infrared fluorescence. Environ Sci Technol 2014;48(3):1973-83.

[28] Yang MH, Kwon S, Kostov Y, Rasooly A, Rao G, Ghosh U. Study of the biouptake of labeled single-walled carbon nanotubes using fluorescence-based method. Environ Chem Lett 2011;9(2):235-41. 
[29] Plata DL, Reddy CM, Gschwend PM. Thermogravimetry-mass spectrometry for carbon nanotube detection in complex mixtures. Environ Sci Technol 2012;46(22):12254-61. [30] Doudrick K, Herckes $P$, Westerhoff P. Detection of carbon nanotubes in environmental matrices using programmed thermal analysis. Environ Sci Technol 2012;46(22):12246-53. [31] Selck H, Handy RD, Fernandes TF, Klaine SJ, Petersen EJ. Nanomaterials in the aquatic environment: a european union-united states perspective on the status of ecotoxicity testing, research priorities, and challenges ahead. Environ Toxicol Chem 2016;35(5):1055-67. [32] Petersen EJ, Flores-Cervantes DX, Bucheli TD, Elliott LCC, Fagan JA, Gogos A, et al. Quantification of carbon nanotubes in environmental matrices: current capabilities, case studies, and future prospects. Environ Sci Technol 2016;50(9):4587-605. [33] Hamdi H, De La Torre-Roche R, Hawthorne J, White JC. Impact of non-functionalized and amino-functionalized multiwall carbon nanotubes on pesticide uptake by lettuce (Lactuca sativa L.). Nanotoxicology 2015;9(2):172-80. [34] De La Torre-Roche R, Hawthorne J, Deng YQ, Xing BS, Cai WJ, Newman LA, et al. Multiwalled carbon nanotubes and C-60 fullerenes differentially impact the accumulation of weathered pesticides in four agricultural plants. Environ Sci Technol 2013;47(21):12539-47. [35] Wild E, Jones KC. Novel method for the direct visualization of in vivo nanomaterials and chemical interactions in plants. Environ Sci Technol 2009;43(14):5290-4. [36] Begum P, Ikhtiari R, Fugetsu B, Matsuoka M, Akasaka T, Watari F. Phytotoxicity of multiwalled carbon nanotubes assessed by selected plant species in the seedling stage. Appl Surf Sci 2012;262:120-4.

533 [37] Lin C, Fugetsu B, Su YB, Watari F. Studies on toxicity of multi-walled carbon nanotubes on 534 Arabidopsis T87 suspension cells. J Hazard Mater 2009;170 (2-3):578-83.

535 [38]Tan X, Lin C, Fugetsu B. Studies on toxicity of multi-walled carbon nanotubes on suspension rice cells. Carbon 2009;47(15):3479-87. [39] Yan SH, Zhao L, Li H, Zhang Q, Tan JJ, Huang M. Single-walled carbon nanotubes selectively influence maize root tissue development accompanied by the change in the related gene expression. J Hazard Mater 2013;246:110-8.

540 [40] Tan XM, Fugetsu B. Multi-walled carbon nanotubes interact with cultured rice cells:

541 Evidence of a self-defense response. J Biomed Nanotechnol 2007;3(3):285-8.

542 [41] Zhao Q, Yang K, Zhang SY, Chefetz B, Zhao J, Mashayekhi H, et al. Dispersant selection 543 for nanomaterials: Insight into dispersing functionalized carbon nanotubes by small polar 544 aromatic organic molecules. Carbon 2015;91:494-505. 
[42] Elghniji K, Salem S, ben Mosbah M, Elaloui E, Moussaoui Y. Detoxification of 4chlorophenol in $\mathrm{TiO}_{2}$ sunlight system: effect of raw and treated solution on seed germination and plants growth of various sensitive vegetables. Toxicol Environ Chem 2014;96(6):869-79. [43] Zaalishvili G, Sadunishvili T, Scalla R, Laurent F, Kvesitadze G. Electron microscopic investigation of nitrobenzene distribution and effect on plant root tip cells ultrastructure. Ecotoxicol Environ Saf 2002;52(3):190-7. [44] Zhao Q, Yang K, Li W, Xing BS. Concentration-dependent polyparameter linear free energy relationships to predict organic compound sorption on carbon nanotubes. Sci Rep 2014;4:7. [45] Petersen EJ, Akkanen J, Kukkonen JVK, Weber WJ. Biological uptake and depuration of carbon nano-tubes by Daphnia magna. Environ Sci Technol 2009;43(8):2969-75. [46]Petersen EJ, Huang QG, Weber WJ. Ecological uptake and depuration of carbon nanotubes by Lumbriculus variegatus. Environ Health Perspect 2008;116(4):496-500. [47] Zhang LW, Petersen EJ, Huang QG. Phase distribution of C-14-labeled multiwalled carbon nanotubes in aqueous systems containing model solids: Peat. Environ Sci Technol 2011;45(4):1356-1362.

[48] Zhao Q, Petersen EJ, Cornelis G, Wang X, Guo X, Tao S, et al. Retention of ${ }^{14}$ C-labeled multiwall carbon nanotubes by humic acid and polymers: Roles of macromolecule properties. Carbon 2016;99:229-37.

[49] Ma CX, Chhikara S, Xing BS, Musante C, White JC, Dhankher OP. Physiological and molecular response of Arabidopsis thaliana (L.) to nanoparticle cerium and indium oxide exposure. ACS Sustain Chem Eng 2013;1(7):768-78.

[50] Holden PA, Gardea-Torresdey JL, Klaessig F, Turco RF, Mortimer M, Hund-Rinke K, et al. Considerations of environmentally relevant test conditions for improved evaluation of ecological hazards of engineered nanomaterials. Environ Sci Technol 2016;50(12):6124-45. [51] Lichtenthaler, HK. [34] Chlorophylls and carotenoids: Pigments of photosynthetic biomembranes. In: Methods in Enzymology, vol 148, Academic Press; 1987 P. 350-82. [52] Kruger NJ. The Bradford method for protein quantitation. In: Basic protein and peptide protocols, Springer; 1994 P. 9-15.

[53] Zhao L, Peng B, Hernandez-Viezcas JA, Rico C, Sun Y, Peralta-Videa JR, et al. Stress response and tolerance of Zea mays to $\mathrm{CeO}_{2}$ nanoparticles: Cross talk among $\mathrm{H}_{2} \mathrm{O}_{2}$, heat shock protein, and lipid peroxidation. ACS nano 2012;6(11):9615-22.

[54] Dixit V, Pandey V, Shyam R. Differential antioxidative responses to cadmium in roots and leaves of pea (Pisum sativum L. cv. Azad). J Exp Bot 2001;52(358):1101-9. 
578 [55] Nair R, Varghese SH, Nair BG, Maekawa T, Yoshida Y, Kumar DS. Nanoparticulate

579 material delivery to plants. Plant Sci 2010;179 (3):154-63.

580 [56] Chichiricco G, Poma A. Penetration and toxicity of nanomaterials in higher plants.

581 Nanomaterials 2015;5(2):851-73.

582 [57] Khodakovskaya MV, Kim BS, Kim JN, Alimohammadi M, Dervishi E, Mustafa T, et al.

583 Carbon nanotubes as plant growth regulators: Effects on tomato growth, reproductive system,

584 and soil microbial community. Small 2013;9(1):115-23.

585 [58] Villagarcia H, Dervishi E, de Silva K, Biris AS, Khodakovskaya MV. Surface chemistry of

586 carbon nanotubes impacts the growth and expression of water channel protein in tomato plants.

587 Small 2012;8(15):2328-34.

588 [59] Giraldo JP, Landry MP, Faltermeier SM, McNicholas TP, Iverson NM, Boghossian AA, et

589 al. Plant nanobionics approach to augment photosynthesis and biochemical sensing. Nature

590 Materials 2014;13(4):400-8.

591 [60] Wang XP, Han HY, Liu XQ, Gu XX, Chen K, Lu DL. Multi-walled carbon nanotubes can

592 enhance root elongation of wheat (Triticum aestivum) plants. J Nanopart Res 2012;14(6):10. 
Quantitative evaluation of multi-wall carbon nanotube uptake by terrestrial plants Graphical Abstract:
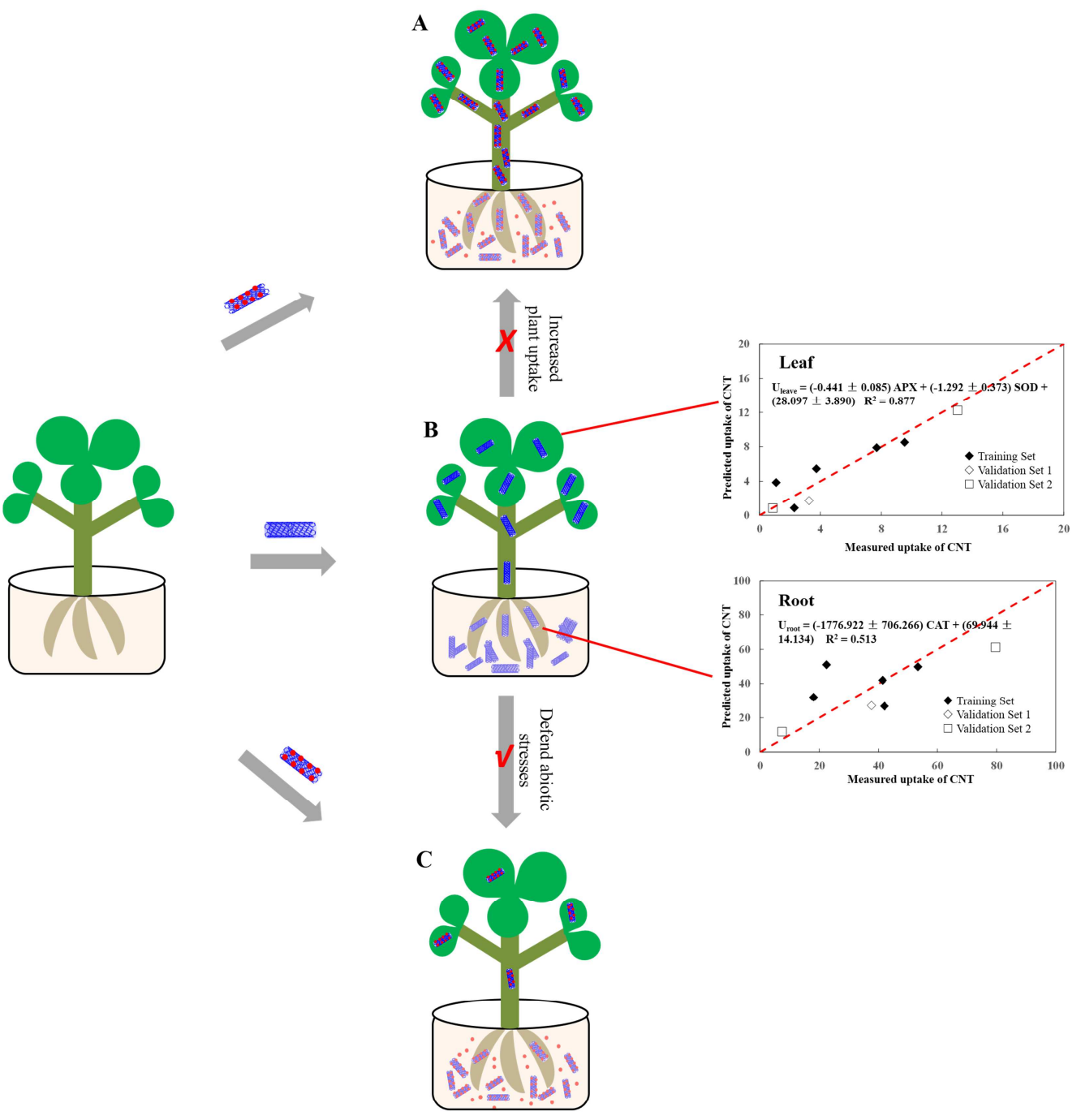